\title{
Debate
}

A conjugação as infâncias pensadas por Descartes e Rousseau duas infâncias exprimiria uma forma singular de o homem experimentar o tempo e o desejo, ou seja, a impossibilidade na relação aos outros. Dessa forma, sustenta-se a tese de que a renúncia à educação é um sintoma contemporâneo que as ilusões psicopedagógicas mascaram a cota de política embutida tanto na produção psíquica da infância moderna quanto no seu eclipse. Infância moderna; filosofia da educaçäo; fundamentos da educação

WHAT IT IS ABOUT CHILDHOOD THAT (PSYCHOIPEDAGOGIC ILIUSION HAS MASKED

The conjugation of the two infancies would express a singular form for man to experiment time and desire, that is to say, the impossibility of a relationship with others. Thus, the author insists on supporting the thesis that renouncing to education is a contemporary symptom, at the same time in which psychopedagogic illusions mask the parcel of politics built into the psychic production of modern infancy, as well as in its demise. Modern childhood; philosophy of education; the fundamentals of education

\section{O QUE DA INFÂNCIA A ILUSÃO (PSICO)PEDAGÓGICA MASCARA}

Leandro de Lajonquière<smiles>CC=CCC</smiles>
ão foi pouca minha alegria e curiosidade quando o prof. Ghiraldelli propôs dialogarmos em torno de Infância e ilusão (psico)pedagógica. Por um lado, o convite ao debate intelectual acarretou a alegre certeza de que a obra tinha sido de fato lida. Por outro, instalou uma dupla curiosidade. $\mathrm{Na}$ época, a leitura de alguns de seus textos alimentou minha reflexão, e, portanto, fui rapidamente tomado pelo interrogante sobre o destino que tinha dado às teses do colega. Mas, fundamentalmente, o fato de o convite vir de um filósofo - ou seja, de alguém que felizmente usufrui de certa disciplina de pensamento que faz falta a nós, psicanalistas - alimentou minha vontade de entregar-me ao risco prazeroso do certo e involuntário mal-entendido próprio de todo diálogo intelectual. Por sinal, diálogo no qual os espíritos burocratas - fora e dentro da universidade - recusam-se a entrar, temerosos de que lhes venha a faltar um pouco de razão, esquecendo, assim, que a razão em excesso, em lugar de nos agraciar com as cobiçadas idéias claras e distintas, apenas cria monstros. 
O prof. Ghiraldelli afirma que em meu livro falo mais do passado que do presente, uma vez que a argumentação articula-se em torno de uma infância que não existiria mais. Mais ainda, como todo professor generoso, aproveita a ocasião para insistir no exercício dessa ilustração, que hoje, infelizmente, escasseia, mostrando-me aspectos que nossa ignorância sempre teima em esconder.

Pois bem, existe a infância de que falo? Sim e não; depende.

Todo adulto, quando fala da infância, fala daquela que não existe mais, uma vez que o tempo dela é aquele do "já foi". Dessa forma, o tempo ido faz com que a infância não cesse de (não) se inscrever em nosso aparelho psíquico sob a modalidade do "terá sido". É por isso que a infância da psicanálise não é uma substância, como aquela das psicologias do desenvolvimento. Mas também é por conta dessa impossibilidade de representação - ou seja, de voltar a se tornar presente - que toda criança nos lembra inconscientemente aquela que nós fomos para outros e, portanto, a dívida simbólica para com aqueles a quem deixamos a desejar. Em suma, em certo sentido, cabe dizer que a infância não existe. Mas parece-me que não se está me perguntando por essa, embora, é claro, eu tenha, sim, falado dela em meu livro.

Certamente, não falei da infância sonhada por Descartes, como parece ler o prof. Ghiraldelli em meu livro, embora seja devedor não só de certo iluminismo, senão também de um humanismo tipicamente freudiano. Mas tampouco falei daquela outra almejada, nas antípodas da anterior, 
aquela do Emílio. Ambas as infâncias não só, hoje, não existem, senão que sempre estiveram, e talvez estejam, impossibilitadas de acontecer. Tanto uma quanto a outra definem os limites virtuais para que uma infância venha de fato a acontecer, a despeito de ambas as pretensões filosóficas. Nesse sentido, concordo com o filósofo quando observa que aquilo que existiu ou operou, por décadas, no cotidiano da "relação adulto-criança" é uma espécie de confusão de ambas. Mais ainda, concordo com que essa "infância mistura" corre o risco de estar chegando a seu fim.

O prof. Ghiraldelli nos lembra que, para Descartes, a infância deve ser superada para que, dessa forma, possa advir no lugar daquela o adulto da modernidade, ou seja, o indivíduo "consciente de seus pensamentos e responsável pelos seus atos”. Por outro lado, lembra-nos que, para Rousseau, o adulto não deve contrariar ou lutar (cartesianamente) contra a infância que se supõe nas crianças, mas, ao contrário, intervir no sentido de que a mesma aconteça, a fim de que, assim, possa vir a ser superada ma non troppo, ou seja, para que um pouco dela fique preservada no adulto. Pois bem, nenhuma delas existe, pois o que ambos os pais da modernidade espiritual pressupuseram é, em última instância, uma infância como dado natural, ora a ser contrariada, ora a ser preservada. A psicanálise contesta, precisamente, essa pressuposição de naturalidade. Mais ainda, chama nossa atenção para o fato de ser a tênue conjunção desses dois sonhos adultos com relação aos "baixinhos" a que fez, e faz, ex/istir ${ }^{1}$, precisamente, o tempo da infância.

Tanto um quanto o outro - o cartesiano e o rousseauniano são isso mesmo, ou seja, dois sonhos filosóficos que, por sua vez, sonham o adulto cotidiano. A contingência cotidiana do homem resiste a ser reintegrada em qualquer sistema filosófico, assim como as crianças resistem aos nossos pedagógicos sonhos adultos. Porém, quando o adulto termina encarnando in extremis qualquer um de ambos os sonhos e, assim, situando-se ao abrigo da interrogação que todo sonho confuso acarreta, acaba não havendo infância. A clínica psicanalítica com crianças gravemente perturbadas ensina-nos a desconfiar dos sonhos que não dão lugar a que o sonhante desconfie que se trata, precisamente, de sonhos e, portanto, que o adulto reclame da criança a ilustração ou a encarnação dos mesmos no real. Assim, cabe dizer, com todas as licenças do caso, que enquanto o autismo é efeito de um sonho que sonha nada dever sonhar para uma criança, as psicoses resultam de um outro que sonha, ao contrário, não deixar margem nenhuma para que uma criança possa vir a sonhar um lugar para si no sonho dos outros. Ambos não são, de fato, sonhos: estão mais para verdadeiros pesadelos. Nesse sentido, poder-se-ia dizer que enquanto um tem algu- 
ma coisa de rousseauniano, o outro parece um pouco cartesiano. Em outras palavras, o primeiro não desconfiaria que o seu pequeno selvagem nunca será suficiente bom, já o segundo não suspeitaria que o adulto esperado estará impossibilitado de ser consciente e responsável pelos atos de "seu" pensamento.

Quando uma criança chega de fato a este mundo, já faz um tempo que o adulto o habita. A chegada do pequeno implica de fato uma reordenação do mundo, já que a criança, não sendo um adulto em miniatura no real, instala uma diferença que, feita tensão temporal, moverá o devir adulto. Todo adulto, quando se endereça a uma criança, demanda-lhe deixar atrás essa sua condição de infans, que, não tendo nada de natural, deriva da própria presença antecipada do adulto no mundo. Mas, ao mesmo tempo, o adulto sabe da impossibilidade de o pequeno responder no real à altura da demanda, ou seja, sabe do tempo próprio à espera. Assim, demanda, enquanto dá tempo ao tempo, apostando no desdobramento da diferença posta na origem. $\AA$ criança, tomada nesse dispositivo temporal e psíquico que no livro chamei de denegação da demanda educativa, sempre lhe escapa o ponto de vista do adulto e, por isso mesmo, não pode menos que lhe supor um saber fazer com a vida. Mais ainda, passa a desejar saber esse saber suposto nos grandes e, dessa forma, embora às vezes de brincadeira, faz questão, uma e outra vez, de entrar num mundo já velho e adulto. Quando por fim chega seu tempo, a criança, agora um adulto, defronta-se com o fato de que o ponto de vista adulto não é tão sabido ássim e que, portanto, o tempo que a própria espera fabricou era apenas para ser perdido. Porém, o novo adulto, longe de se resignar, ensaia recuperar o tempo, ora fazendo filosofia ou psicanálise, ora educando crianças, desconfiando sempre um pouco de que tal empresa esteja garantida no ponto de partida.

Como vemos, a introdução da criança no real de uma história em curso não faz mais do que instaurar uma tensão no campo do discurso entre o lado de lá - o do infans - e este outro de cá - o do adulto. Em que ambos não são pontos de uma linha genéticoevolutiva rumo - seja na marra ou não - a uma razão mais ou menos iluminada, mas posições no discurso com relação ao desejo. Para que semelhante giro de posição aconteça, é necessário que o adulto tome como metáfora o desencontro no real com esse pequeno ser no mundo. Educar é, precisamente, isso. Ou, em outras palavras, é transmitir marcas simbólicas - inventar metáforas - que possibilitem ao pequeno sujeito usufruir de um lugar a partir do qual possa se lançar às empresas impossíveis do desejo. Esse giro de posição no discurso é a própria condição de possibilidade de que venha a existir um tempo de infância. Quando o infans deixa de 
ser tal, a infância passa a existir como perdida, mas não toda. $O$ que resta desse (des)encontro com o adulto, em parte, inscreve-se psiquicamente como desejo sexual e infantil, ou seja, como aquilo que passa a fazer falta num mundo sempre adulto. Já uma outra parte desse (des)encontro, ou falta de relação (rapport) adultocriança, permanece como gozo.

Pois bem, para tanto, ou seja, para que tudo isso ${ }^{2}$ se desdobre, não é preciso fazer muita coisa. Mais ainda, é, até certo ponto, irrelevante aquilo que os adultos deliberem perseguir como metas pedagógicas ${ }^{3}$. Entretanto, também não é sem conseqüências, e, portanto, cabe afirmar que esse funcionamento simbólico é objeto de inflexões múltiplas.

O homem sonha-se a si mesmo e, assim, inventa-se sempre outro. $\mathrm{Na}$ chamada modernidade, passou a se relacionar consigo mesmo, ou seja, a experimentar o tempo, de maneira nova. $\mathrm{Na}$ época, aquilo que sempre resta em seus sonhos deixou de ser creditado a um paraíso perdido no passado e passou a ser buscado neste mundo de homens. O homem moderno lançou-se à sua procura, mesmo sabendo que isso sempre falta ao encontro, pois está sempre num outro lugar neste nosso único mundo humano. Isso que passou a se esperar para o amanhã aqui na terra - e fora chamado utopia - foi esculpindo aos poucos o rosto da infância nesses seres pequenos. A insatisfação pulsional, implicada no mal-estar na cultura, outrora equacionada graças à referência a um passado vivido em companhia dos deuses, na modernidade, insuflou, ao contrário, a idéia 
de um futuro diferente aqui na terra. Assim sendo, virou matéria-prima para se inventar a infância moderna, uma vez que a criança, tendo chegado depois que os adultos, faz-se rapidamente depositária imaginária de uma diferença temporal a mais.

A infância, uma espécie de coágulo dos sonhos que o homem moderno passou a sonhar para si, é um ponto numa trama contraditória e, portanto, encerra em si mesma uma tensão de equacionamento delicado. A infância moderna é o ponto de fuga no horizonte dos sonhos adultos, em que se tocam de forma assintótica desejo e narcisismo.

$O$ adulto moderno acabou se entregando ao sonho de um mundo diferente, de um mundo em que imperasse, por exemplo, a liberdade, a igualdade e a fraternidade. Essa figuração da utopia, em particular, foi sonhada, disputada e reivindicada com insistência por muitos. Ela resumiu uma maneira nova de o homem interrogar-se sobre o impossível que permeia sua relação com seus semelhantes, ou seja, implicou uma outra economia psíquica do desejo ${ }^{4}$.

$\mathrm{O}$ adulto moderno passou a esperar que a criança viesse a usufruir no futuro esse outro mundo terreno, mas também se dedicou a instalar na cabeça dela o sonho de sua possibilidade. Assim, a diferença criança/adulto virou objeto de máxima tensão psíquica e social. No revoltoso século XIX, a escola "laica, gratuita e obrigatória" foi a figuração institucional mais acabada da infância moderna de fato, verso e reverso de uma mesma moeda, objeto de disputas políticas. O usufruto da escola republicana foi reivindicado como direito, a despeito da vontade de alguns, que sempre querem que os direitos sejam de fato privilégios de poucos. Por quê? Porque todos intuíam que ela detinha a chave de acesso à infância. A escola incorporou a tensão narcisismo/desejo embutida na infância, e, assim, além de ter exprimido, como toda instituição, um projeto de moralização, funcionou como uma máquina movida a desejo possuidora de grande força subjetivante.

A infância que estamos perdendo e da qual eu falei no livro é precisamente essa, isto é, o dispositivo discursivo que tenciona o cotidiano das crianças no sentido de se tentar a impossível conversão do real em ideal.

Não falei dela para reclamar respeito a não se sabe que naturalidade, mas apenas para alertar que as ilusões (psico)pedagógicas, pão nosso de cada dia, mascaram, hoje, a perda de uma infância que, em suma, carrega consigo o sonho de o homem vir a inventar um mundo mais justo na polis. E isto o que me preocupa.

A infância (psico)pedagogizada seja de ricos ou de pobres - é uma pseudo-infância esvaziada de desejo. E por isso que ela impera entre nós. Ela resulta do estreitamento da dialética psíquica dos tempos em cujas entrelinhas articula-se o desejo. Assim, não devemos nos surpreender de que as crianças recusem o mundo dos números e das letras, enquanto preferem o imediatismo próprio das coisas, como, por exemplo, as drogas. É claro, a diferença de classes dá seu toque de distinção a essa pseudo-infância, affaire de gozo. 
O risco de vir a desaparecer a infância moderna é o sintoma de um mundo adulto que, não querendo saber mais da exigência de se tentar o impossível de um sonho ${ }^{5}$ - educar as crianças -, entrega-se ao pesadelo dos mercados mais variados, enquanto se autoperdoa exclamando: "Fazer o quê? É assim mesmo!"

\section{NOTAS}

1 Ou seja, existir fora de si, ou ser arrojado no tempo.

2 Leia-se $o$ inconsciente.

3 O que não quer dizer que seja irrelevante o que os adultos decidam fazer com a vida na polis.

4 Cf. Lajonquière, L. de. "Psicanálise, modernidade e fraternidade. Notas introdutórias". In Kehl, M. R. (org.). A função fraterna. Rio de Janeiro, RJ: Relume Dumará, 2000.

5 Cf. Lajonquière, L. de. "Freud, l'éducation et les enfants: entre la psychanalyse et la politique". In États généraux de la psychanalyse. Paris, 2000. 